Psychological Medicine, 1979, 9, 611-618

Printed in Great Britain

\title{
EDITORIAL
}

\section{Schizophrenia and physical disease ${ }^{1}$}

In the 2000 years since Hippocrates noted that fever sometimes alleviated psychotic behaviour an extensive speculative, theoretical and observational literature has accumulated about the relation between physical illness and psychosis. Yet, in 1977, Lipper \& Werman concluded that 'prospective, well controlled investigations on the relationship between schizophrenia and physical illness remain to be performed'. The proportion of methodologically sound observational studies, mainly of mortality, certainly is small. There is fairly general agreement that, compared with the community population as a whole, the relative risk of death in schizophrenia is increased, probably about twofold, and is slightly higher in females than in males. Most studies agree also that the excess risk of death declines as age increases and as length of hospital stay increases. The largest excess mortality tends to occur in the first year after referral or hospital admission, raising the possibility of selective referral of physically ill patients (Malzberg, 1953; Innes \& Millar, 1970). Thus, unless Ødegaard's (1952) dictum is accepted, that nearly all schizophrenics, at least until recent times, eventually found their way into hospital, there must be doubt about the validity of apparently raised relative risks from specific causes of death. Babigian \& Odoroff (1969) found that the chronically ill, the aged and alcoholics contributed most of the excess deaths. Suicide and other traumata are the commonest causes of death in most recent studies.

Reduced relative risks always call in question the thoroughness of ascertainment among the case population. Special caution must therefore be exercised in reviewing the evidence for positive or negative associations of particular diseases with schizophrenia, in addition to the usual uncertainties surrounding the psychotic diagnosis itself. Virtually all the research so far reported antedates the standardization developed for the WHO International Pilot Study, though the earlier studies at least avoided much of the risk of bias resulting from drug therapy in the last 25 years.

The choice of method is critical to robust determination of disease linkages with schizophrenia. Most studies that have not relied simply on proportionate mortality (the proportion of deaths from the specified disease in schizophrenics compared with the proportion in a control population) have compared sex- and age-specific death rates among schizophrenics with general population rates. The small number of morbidity studies, particularly of cancer, have generally used some variant of this technique also. Schizophrenia is not a very common condition, with an annual incidence which may be as low as 1 per 1000 (Baldwin, 1971; Cooper, 1978) and, although sound in principle, the difficulty of assembling large enough numbers of cases has restricted most such studies to generalities, such as the relative risk of any cancer among all schizophrenics, whereas to be of value in testing aetiological hypotheses it would be highly desirable, if not essential, to ascertain statistical associations between specific diseases and various subtypes of schizophrenia in individuals. A more difficult and more expensive method, but one which would eliminate much of the uncertainty, would be to compare outcomes of cohorts of cases and matched controls with respect to incidence of supposedly associated diseases (Baldwin, 1977). The controls would have to provide for the possibility that diseases linked with schizophrenia might also be linked with other psychoses or even be characteristic of psychiatric disorder generally. A good example of this type of design is the Iowa City follow-up study of discharged psychiatric patients (Tsuang \& Woolson, 1977).

Another potentially powerful device for this purpose is a system of linked personal medical records obtained from a range of health services covering a defined population at risk. The Oxford Record Linkage Study (ORLS) (Acheson, 1967; Baldwin, 1973) has demonstrated the feasibility of such a scheme at remarkably low cost, since it makes use of existing data collections such as the

1 Address for correspondence: Dr J. A. Baldwin, Oxford University Unit of Clinical Epidemiology, Oxford Regional Health Authority, Old Road, Headington, Oxford OX3 7LF.

0033-2917/79/2828-4700\$01.00 (C) 1979 Cambridge University Press 
Hospital Activity Analysis and Mental Health Enquiry systems which already cover England and Wales. It has been shown that the Oxford linked data can be used to estimate statistical linkages between diseases in individuals taking account of many of the confounding variables, including period at risk, sex, the cohort effect upon age, mortality, seasonal, secular and epidemic trends in disease incidence, migration, and residential area (Adelstein et al. 1979; Baldwin \& Wing, 1978; Baldwin et al. 1979). The main limitations of this study are the small population covered (800000), the short time period (at present a nominal 8 years giving a mean period at risk of under 4 years), and the restriction to in-patient discharge and mortality data. Out of 367000 patients there were 2314 schizophrenics. These limitations are not insuperable and the approach perhaps offers the best hope of elucidating the complex patterns of disease risks which have been suggested as possibly being associated with schizophrenia and which may have an important bearing on aetiology.

At least 20 diseases have been claimed or hypothesized to be positively associated with schizophrenia and a further 6 negatively associated. The most extensively studied or most important of these from the point of view of current aetiological theories are reviewed with the object of drawing attention to those most likely to repay further study.

\section{CANCER}

The risk of cancer in schizophrenics is the most frequently researched topic in this field. The earliest commonly cited reference is the report for 1909 of the Board of Control (Commissioners in Lunacy, 1909 ) in which it was suggested that the insane enjoyed some immunity from cancer. A considerable number of studies between the two World Wars claimed the relative rarity of malignancy among the insane, and particularly among schizophrenics (Büel, 1925; White, 1929; Pool, 1930; Chevens, 1931; Hahnemann, 1931; Warren \& Canavan, 1934), and Fox \& Howell (1974) in a brief review cite several other studies between 1946 and 1969. The majority of these studies, including most recently that of Rassidakis et al. (1971), were based on proportionate mortality and thus did not yield valid estimates of relative risk.

Another larger group of studies has not confirmed this conclusion, citing frequencies of cancer equal to or greater than those in the general population (Copeman \& Greenwood, 1926; Lind, 1928; Lord \& McGrath, 1930; Opsahl, 1933; Rudolph \& Ashby, 1934; Alström, 1942; Malzberg, 1950; Scheflen, 1951; Ehrentheil, 1956; Ødegaard, 1951, 1967; Babigian \& Odoroff, 1969; Innes \& Millar, 1970; Ananth \& Burnstein, 1977). Most of these studies were sex- and age-specific comparisons of cancer rates with general population rates. Some were based on autopsies, though some used clinical diagnoses and included both morbidity and mortality. Not all differentiated separate classes of mental disorders. The results are not wholly consistent. For example, Malzberg (1950) found higher cancer death rates in New York State mental hospitals among younger patients, but significantly lower rates among elderly patients. The age-standardized male rate was lower than the general population rate and the female rate was higher, giving a marginally low total adjusted rate. Only one study of comparative rates has demonstrated a significant reduction in relative risk for cancer among schizophrenics as a whole (Rassidakis et al. 1973) and only one derived a significant excess (Ananth \& Burnstein, 1977). A few studies have attempted to calculate risks for subcategories of schizophrenia. Scheflen (1951) found increased cancer mortality rates among paranoid schizophrenics who tended to die at an earlier age, but this was not confirmed by Ehrentheil (1956) on the basis of clinical morbidity. Hussar (1966), using a partially corrected form of proportionate mortality, suggested that there was a lower proportion of cancer deaths among catatonics. There have been few indications of correlations with specific cancers. Opsahl (1933) reported an excess of cancer of the stomach, Lord \& McGrath (1930) and Scheflen (1951) found an unusually high incidence of cancer of the pancreas, and Hussar (1966) noted a significantly high proportion of lung cancer. Beattie (1966) reported an increased proportion of fatal blood dyscrasias in the period 1951-63, and Baur (1967) suggested the excess might be accounted for by phenothiazine sensitivity.

The most important study of cancer in mental patients is that of Katz et al. (1967) on mortality in New York State mental hospitals in the period 1955-61. They showed unequivocally that total 
cancer mortality in mental patients was much higher than in the general population, but that most of the excess occurred among patients with short periods of hospitalization. With hospital stays of 10 years or more, combined rates for all sites were lower than in the general population, particularly among those aged 65 and over. Nevertheless, rates for specific sites varied widely. Significant reductions in relative risk were found among long-stay elderly patients for cancers of the lung, gastrointestinal system, and certain other sites, such as prostate and bladder. Increased relative risks were found for cancers of the oesophagus and pancreas among long-stay elderly men. Long-stay patients under 65 had increased relative risks for a number of sites. The authors pointed out that selective admission and the high average age on admission could account for the very high risks among short-stay patients, while the smoking, dietary and other environmental regimens of longstay patients were likely to exert a general effect on the cancer rates susceptible to these factors. They did not differentiate diagnostic groups of mental disorders, but the findings suggest that any reduction of cancer rates is not specific for schizophrenia, while the higher rates in younger longstay patients, among whom schizophrenia might be expected to be more prevalent, hint that schizophrenics may exhibit a different pattern of risk from most other mental patients.

Despite the poverty of evidence, the idea of reduced risk of cancer in schizophrenia is still attractive because of its potential aetiological importance, and has led WHO to stimulate new studies in 6 centres with psychiatric and cancer registries as part of the large programme of Study of the Outcome of Severe Mental Disorders which has been developed from the successful International Pilot Study of Schizophrenia. The centres are in Denmark (Aarhus), Moscow, Nagasaki, Hawaii, Rochester, N.Y., and Oxford (ORLS). To date, only preliminary and unverified results from the Oxford data are available and these showed no significant differences from expected incidences of the commonest cancers or all cancers among the group of schizophrenias as a whole, or in the control groups of affective psychoses and non-psychotic depressions (Baldwin, 1979). There was a significant excess of cancer of the oesophagus in schizophrenia as a whole, cancer of the stomach among the non-specific schizophrenias, and a marginally significant excess of cancer of the breast among hebephrenic women. Ettigi et al. (1973) suggested that breast cancer might be more common with phenothiazine treatment.

A general excess or diminution of risk of all malignancy in all schizophrenias is almost inconceivable. To be of value in aetiological understanding there must be sufficient material to estimate the relationship between specific tumours and at least some subclasses of schizophrenics. Clemmeson (1978) considered it would be necessary to follow about 10000 schizophrenics for 20 years for full definition of the relationship. Only the Danish data approach this ideal.

\section{CARDIOVASCULAR DISEASE}

The classical mortality studies of Alström (1942) and Ødegaard $(1951,1967)$ are broadly in agreement that the risk of death from the large group of cardiovascular diseases is higher in schizophrenia than in the general population, but the excess is much less for these patients than for other mental patients. Furthermore, the relative risk is considerably greater in younger acute patients than in older patients and the chronic stages of the disease, where it may not differ from expectation.

$\varnothing$ degaard (1967) differentiated coronary heart disease in this group and reported that mortality was slightly but consistently increased over expectation in males aged 50-69 and females aged 40-69. Results from the ORLS preliminary study gave a significant increase in relative risk of arteriosclerotic heart disease in schizophrenics but no difference from expected values for other forms of cardiac, hypertensive or other circulatory diseases. The increased risk of heart disease was not specific for schizophrenia.

\section{INFECTIOUS DISEASES}

The high mortality rates from infectious diseases, particularly tuberculosis, pneumonia and gastrointestinal infections, reported for periods up to the 1940s, were shown not to be specific for schizo- 
phrenia but were characteristic of the mental hospital populations as a whole. Studies covering more recent times confirm the decline and virtual disappearance of mortality from tuberculosis, and a lower though still excessive mortality from pneumonia and other infectious disease. Results from the ORLS preliminary analyses were in accord with significant increases in risk for pneumonia and other respiratory diseases following schizophrenia, affective psychoses and non-psychotic depressions. An interesting additional finding was a highly significant excess of pulmonary tuberculosis prior to admission for schizophrenia. Non-psychotic depression was also associated with pulmonary tuberculosis.

\section{EPILEPSY}

The view attributed to Meduna, that epilepsy and schizophrenia are antagonistic, did not survive following the investigation by Slater \& Beard (1963) of schizophrenia-like psychoses following epilepsy. Reynolds (1968) hypothesized that the biochemical disturbance in epileptics renders them less prone than the normal population to schizophrenia and that the schizophrenic is less liable than the normal subject to develop epilepsy. Levi \& Waxman (1975) elaborated the biochemical hypothesis in relation to methionine and folate metabolism. The parallel search for pathological changes in the limbic system in schizophrenics which are found in temporal lobe epilepsy has not been particularly successful (Torrey \& Peterson, 1974), though Taylor (1975) found a significant increase of schizophrenia in epileptics with temporal lobe tumours and dysplasias compared with epileptics with mesial temporal sclerosis. The ORLS preliminary study did not confirm a relationship between schizophrenia and either focal or minor epilepsy. There were significant elevations of relative risk of major epilepsy following paranoid schizophrenia and prior to unspecified schizophrenia, and of both unspecified epilepsy and epileptic psychosis before and after paranoid and unspecified schizophrenia. Some forms of epilepsy were also found to be associated with affective psychoses and depression. It seems that the relationship between epilepsy and mental disorder is complex in the extreme.

\section{PARKINSON'S DISEASE}

Parkinsonism is a well recognized side-effect of phenothiazine therapy. Recently, Crow et al. (1976) have provided evidence of a specific schizophrenia-like episode occurring in the course of longstanding Parkinsonism which may be relevant to the 'dopamine hypothesis' of the aetiology of schizophrenia. The ORLS preliminary study showed a just significant increase in the relative risk of Parkinsonism following schizophrenia, and similar increases were also found following affective psychoses and neurotic depression. There were increases in the relative risks of schizophrenia, affective psychosis and depression following Parkinsonism, but this was significant only for nonpsychotic depression.

\section{RHEUMATOID ARTHRITIS}

Nissen \& Spencer (1936) appear to have been the first to propose that rheumatoid arthritis and schizophrenia are mutually exclusive conditions. Ehrentheil (1957) believed the acute stages to be very rare, though rheumatoid deformities were sometimes observed. Acute exacerbations alternating with the psychosis have been reported. Mellsop et al. (1974) cited 6 reports between 1939 and 1963 of the rarity of coincidence of the 2 conditions in the same individual. In their own study of 301 middle-aged schizophrenic women they found neither clinical nor radiological evidence of rheumatoid arthritis. This was a highly significant deficit compared with prevalence studies in the general populations of 6 countries. In contrast, rheumatoid factor was demonstrated in the same proportion of patients as in subnormal and normal controls. Osterberg (1978), in a recent extensive study, also found a reduced risk, though there were several co-incidental cases. The ORLS preliminary study showed a significant reduction in relative risk among schizophrenics as a whole, there being only 
1 confirmed and 1 possible case of non-specific schizophrenia compared with 6 expected in the whole group of 2314 schizophrenics. This finding must be interpreted with caution, since rheumatoid arthritis can often be treated without transfer to another facility and would not then be reported to the study. Nevertheless, there was no difference from the expected values of relative risk among manic-depressives and depressives. Osterberg (1978) pointed out that, if the negative association were specific for schizophrenia, a genetic or biochemical explanation would be more likely than if it were a general feature of psychotic or other psychiatric illness. Several studies have now found a low relative risk of rheumatoid arthritis in schizophrenia and none has reported a normal or increased risk. Thus this relationship could prove to be a useful lead for aetiological research.

\section{COELIAC DISEASE}

The first suggestion that symptoms in schizophrenia might be related to ingestion of gluten was made in Greece during the 1939-45 war (Lancet, 1976). Dohan (1966a, b) formulated the hypothesis that gluten sensitivity is causally associated with schizophrenia from studies of international correlations between cereal consumption and estimates of the incidence of schizophrenia, and he submitted evidence from a variety of sources that coeliac disease and schizophrenia are associated in individuals more often than expected by chance (Dohan, 1970). He and his colleagues claimed more rapid improvement in relapsed schizophrenics on a cereal-free, milk-free diet (Dohan et al. 1969; Dohan \& Grasberger, 1973). Dean et al. (1975) screened 166 schizophrenics for folate deficiency and obtained intestinal biopsies from 12 out of 14 patients with low levels but could find no evidence of histological or biochemical abnormality. Reticulin antibody screening and duodenal biopsy were carried out by Stevens et al. (1977). No morphological or histological features of untreated coeliac disease were found, and the incidence of reticulin antibodies was similar in probands and controls. Singh \& Kay (1976) studied the reactions of 14 schizophrenics to gluten challenge and concluded that wheat gluten is pathogenic in schizophrenia. Levy \& Weinreb (1976) and Smith (1976) cast doubt on the statistical validity of this study and it must be accepted that the case is not proven. The ORLS preliminary study yielded a just significantly raised relative risk of malabsorption among all schizophrenics. A significant increase in the prevalence of epilepsy, particularly focal epilepsy, has been reported among patients with coeliac disease (Chapman et al. 1978) and this was confirmed in the ORLS data. Whether anything is to be gained from further study of the triad schizophrenia, coeliac disease and focal epilepsy is an open question, though malabsorption and focal epilepsy were both associated with rheumatoid arthritis.

\section{ASTHMA AND HAY FEVER}

There have been many reports of reduced incidence of asthma, hay fever, and other allergic phenomena in schizophrenics (Ehrentheil, 1957; Lipper and Werman, 1977). There are many case reports of alternating psychotic and allergic states and others in which allergy and psychosis "coexisted' (Sabbath \& Luce, 1952). The role of histamine was studied by several investigators, but Matthysse \& Lipinski (1975) considered that the results were inconclusive because the effect of phenothiazines had not been eliminated and the validity of the blood estimations was in doubt. The ORLS preliminary study yielded low relative risks for these conditions but well within chance limits, whereas there were highly significantly increased relative risks following manic-depressive reactions and neurotic depression.

\section{A STRATEGY FOR RESEARCH}

So far research into disease associated with schizophrenia has tended to concentrate on ascertaining whether risks are raised or lowered to test clinical observations or frankly speculative suggestions. In general, the firmer the conclusions the more mundane and aetiologically uninteresting they have been, while the occasional intriguing findings have not inspired confidence in their validity. Yet 
even the sceptical epidemiologist must suspect that something may be going on which needs elucidating. He will seek significant differences in relative risks for defined diseases specific for schizophrenia and no other psychiatric or non-psychiatric category and which can be shown to be unassociated with general variables, such as length of hospitalization, social class, diet, smoking, and drug treatment. Obviously, he will prefer standardized diagnostic criteria but will recognize that, in practice, the low probabilities and the long time spans involved with rare and chronic conditions and long latent periods likely to be of greatest importance will force him to make do with relatively poorly standardized but larger collections of retrospective data. The best he can hope for is some broad typing of schizophrenia along Kraepelinian lines. Fortunately, he knows from experience that such uncertainties are not necessarily bars to useful work, recalling that most of our epidemiological knowledge has come from relatively unreliable mortality data. He will be more concerned about incomplete ascertainment of disease in schizophrenics.

Although the general search for unexpected statistical associations between schizophrenia and other diseases could prove fruitful in large, readily searched collections of information such as the ORLS, the preferred approach will be to test specific predictions from the better formulated hypotheses, mainly of genetic, biochemical or immunological origin.

The possibility of an autoimmune or other antigenic component in the aetiology of schizophrenia has been part of the motivation for a series of studies of human leukocyte antigens (HLA) in these patients, though the main interest is the search for a genetic marker (McGuffin et al. 1978). The HLA system is known to be related in specific ways to a wide range of diseases, including some of those postulated to be positively or negatively associated with schizophrenia, such as coeliac disease and rheumatoid arthritis. Cross association between such combinations and the HLA system would be particularly helpful, while detection of a gene abnormality would greatly clarify the strong, but as yet non-specific, evidence of a genetic element in schizophrenia (Shields, 1978) and might lead to synthesis of the scattered biochemical evidence of one or more metabolic defects. Böök et al. (1978) have reported results from a study of 30 possible genetic markers, only one of which was positive.

Gilka (1975) reviewed the biochemical evidence and concluded that schizophrenia is caused by one or more inborn errors of metabolism somewhere in the tryptophan-niacin pathway. A group of 'secondary' schizophrenias was postulated, and this hypothesis predicted association with a number of conditions, including starvation, pellagra and nicotinic acid encephalopathy, coeliac disease and malabsorption, impaired liver function, porphyria, hepato-lenticular degeneration, Hartnup's disease, homocystinuria, pernicious anaemia and some blood dyscrasias, hypo- and hyperthyroidism, adrenal insufficiency, hypopituitarism and other causes of hypoglycaemia. Although testable in principle, verification of most of these predictions would require large numbers of schizophrenics with other well-documented pathologies. Nevertheless, it may be worth noting that significant increases in relative risks of myxoedema were found in the ORLS preliminary study in both catatonics and the non-specific schizophrenias, though the relative risk was also high in both the depressive groups.

Horrobin (1979) has attempted to weave 7 biochemical concepts into a unitary hypothesis of deficiency of prostaglandin $E_{1}$. This hypothesis entails several predictions of diseases associated with schizophrenia. Myxoedema would be more common than expected. Rheumatoid arthritis should be uncommon except in periodic catatonia and schizo-affective states. If zinc deficiency were a factor, acrodermatitis enteropathica should be associated. Myasthenia gravis has been said to be rare in schizophrenics (Gittleson \& Richardson, 1973), and the hypothesis suggests that prostaglandin production may be increased in this condition. Unfortunately, epidemiological testing of predictions of such rare associations is impracticable at present. For instance, the expected number of cases of myasthenia gravis among the 2314 schizophrenics from a population at risk of about 800000 in the ORLS preliminary study covering 8 years was only $1 \cdot 1$.

This point emphasizes the difficulty in testing hypothetical postulates entailing epidemiological observation, the great importance of collecting very large numbers of well-documented cases from defined populations at risk and the danger of drawing misleading conclusions through deficient ascertainment. Most of the suggested 'antagonisms' and supposed deficiencies of diseases in schizo- 
phrenia, including cancers, epilepsies, allergies, diabetes and myasthenia gravis, have arisen from interpretations of clinical 'non-experience' based on more or less impressionistic overestimations of what is to be expected by chance. There is not as yet sufficient sound epidemiological evidence for any of them and the only negative association for which the evidence is now fairly strong is that with rheumatoid arthritis. The risks for a few common diseases do seem to be higher in schizophrenia, but often they are high also in other groups of psychiatric patients and, where this is the case, they are not likely to be important in the aetiology of schizophrenia. Associations with a number of rare disorders can be predicted from current aetiological hypotheses, but observational data to estimate many of these are not yet available. The small number of potentially important associations with more common diseases such as epilepsy, Parkinson's disease, and rheumatoid arthritis are amenable to investigation with present data and seem most likely to repay further study.

\section{J. A. BALD WIN}

\section{REFERENCES}

Acheson, E. D. (1967). Medical Record Lirkage. Oxford University Press: London.

Adelstein, P., Baldwin, J. A. \& Fedrick, J. (1979). Cancers of the large bowel: associated disorders in individuals. Cancer (in the press).

Alström, C. H. (1942). Mortality in mental hospitals with special regard to tuberculosis. Acta Psychiatrica et Neurologie, Supplement no. 24.

Ananth, J. \& Burnstein, M. (1977). Cancer: less common in psychiatric patients? Psychosomatics 18, 44-46.

Babigian, H. M. \& Odoroff, C. L. (1969). The mortality experience of a population with psychiatric illness. American Journal of Psychiatry 126, 52-62.

Baldwin, J. A. (1971). Aspects of the Epidemiology of Mental Illness: Studies in Record Linkage. Little, Brown: Boston, Mass.

Baldwin, J. A. (1973). Linked record medical information systems. Proceedings of the Royal Society, London, B 184, 403-420.

Baldwin, J. A. (1977). Assessment of General Morbidity of Psychiatric Patients Based upon Case Registers. World Health Organization: Geneva.

Baldwin, J. A. (1979). Schizophrenia and physical disease: a preliminary analysis of data from the Oxford Record Linkage Study. Paper delivered to the Schizophrenia Association of Great Britain, May 1979.

Baldwin, J. A. \& Wing, J. K. (1978). Disease associations in linked records: schizophrenia and accidental injury. British Journal of Psychiatry 133, 445-447.

Baldwin, J. A., Fedrick, J., Gill, L. E. \& Simmons, H. (1979). Linked diseases in individuals. Submitted for publication.

Baur, E. W. (1967). Anaemia and reticulum cell hyperplasia in schizophrenia. British Journal of Psychiatry 113, 558.

Beattie, M. K. (1966). Anaemia and reticulum cell hyperplasia in schizophrenia. British Journal of Psychiatry 112, 12851286.

Böök, J. A., Wetterberg, L. \& Modrzweska, K. (1978). Schizophrenia in a North Swedish geographical isolate, 1900-1977: epidemiology, genetics and biochemistry. Clinical Genetics 14, 373-394.

Büel, E. S. (1925). Maligne Tumoren bei Geisteskrankenheiten. Allgemeine Zeitschrift für Psychiatrie 80, 312-321.

Chapman, R. W. G., Laidlow, J. M., Colin-Jones, D., Eade, O. E. \& Smith, C. L. (1978). Increased prevalence of epilepsy in coeliac disease. Lancet ii, 250-251.

Chevens, L. C. F. (1931). The correlation of cause of death with type of insanity. Journal of Mental Science 77, 562-572.

Clemmeson, J. (1978). Report of the Meeting of Investigators Collaborating in the Study of General Morbidity of Psychiatric Patients and their Families. World Health Organization: Geneva.
Commissioners in Lunacy for England and Wales (1909). Annual Report. HMSO: London.

Cooper B. (1978). Epidemiology. In Schizophrenia: Towards a New Synthesis (ed. J. K. Wing), pp. 31-51. Academic Press: London.

Copeman, S. M. \& Greenwood, M. (1926). Ministry of Health, Report No. 36. HMSO: London.

Crow, T., Johnstone, E. C. \& McClelland, H. A. (1976). The coincidence of schizophrenia and Parkinsonism: some neurochemical implications. Psychological Medicine 6, 227-233.

Dean, G., Hanniffy, L., Stevens, F. M., Temperley, L., O'Broin, J. D., Scott, J. \& Cahalane, S. F. (1975). Schizophrenia and coeliac disease. Journal of the Irish Medical Association 68, 545-546.

Dohan, F. C. (1966a). Wartime changes in hospital admissions for schizophrenia: a comparison of admissions for schizophrenia and other psychoses in six countries during World War II. Acta Psychiatrica Scandinavica 42, $1-23$.

Dohan, F. C. $(1966 b)$. Cereals and schizophrenia: data and hypothesis. Acta Psychiatrica Scandinavica 42, 125-152.

Dohan, F. C. (1970). Letter. Lancet i, 897-898.

Dohan, F. C. \& Grasberger, J. C. (1973). Relapsed schizophrenics: earlier discharge from the hospital after cerealfree, milk-free diet. American Journal of Psychiatry 130, 685-688.

Dohan, F. C., Grasberger, F. M., Lowell, H. T., Johnston, A. \& Arbegast, W. (1969). Relapsed schizophrenics: more rapid improvement on a milk and cereal-free diet. British Journal of Psychiatry 115, 595-596.

Ehrentheil, O. F. (1956). Malignant tumors in psychotic patients. Archives of Neurology and Psychiatry 76, 529-535.

Ehrentheil, O. F. (1957). Common disorders rarely found in psychotic patients. Archives of Neurology and Psychiatry 77, 178-186.

Ettigi, P., Lal, S. \& Friesen, H. G. (1973). Prolactin, phenothiazines, admission to mental hospital and carcinoma of the breast. Lancet ii, 266-267.

Fox, B. H. \& Howell, M. A. (1974). Cancer risk among psychiatric patients: a hypothesis. International Journal of Epidemiology 3, 207-208.

Gilka, L. (1975). Schizophrenia: a disorder of tryptophan metabolism. Acta Psychiatrica Scandinavica Supplement no. 258.

Gittleson, N. L. \& Richardson, T. D. E. (1973). Myasthenia gravis and schizophrenia - a rare combination. British Journal of Psychiatry 122, 343-344.

Hahnemann, V. (1931). Cancer mortality and mental disease. Ugeskrift for Laeger 93, 1132-1139.

Horrobin, D. F. (1979). Schizophrenia: reconciliation of the dopamine, prostaglandin, and opioid concepts and the role of the pineal. Lancet i, 529-531. 
Hussar, A. E. (1966). Leading causes of death in institutionalized chronic schizophrenic patients: a study of 1275 autopsy protocols. Journal of Nervous and Mental Disease 142, 45-57.

Innes, G. \& Millar, W. M. (1970). Mortality among psychiatric patients. Scottish Medical Journal 15, 143-148.

Katz, J., Kunoesky, S., Patten, R. E. \& Allaway,N. C. (1967). Cancer mortality among patients in New York mental hospitals. Cancer 20, 2194-2199.

Lancet (1976). Gluten and schizophrenia, i, 844.

Levi, R. N. \& Waxman, S. (1975). Schizophrenia, epilepsy, cancer, methionine and folate metabolism. Lancet ii, 11-12.

Levy, D. L. \& Weinreb, H. J. (1976). Letter. Science 194, 448.

Lind, W. A. T. (1928). Cancer and chronic insanity. Medical Journal of Australia 2, 378-379.

Lipper, S. \& Werman, D. S. (1977). Schizophrenia and intercurrent physical illness: a critical review of the literature. Comprehensive Psychiatry 18, 11-22.

Lord, J. R. \& McGrath, M. J. (1930). The incidence of cancer in mental hospital patients and in the general population of England and Wales compared. Royal Medico-Psychological Association Report. Journal of Mental Science 76, 223-233.

Malzberg, B. (1950). Mortality from cancer among patients with mental disease in New York Civil State hospitals. Psychiatric Quarterly Supplement 24, 73-79.

Malzberg, B. (1953). Further studies of mortality among patients with mental disease. Acta Medica Scandinavica 277, 215-230.

Matthysse, S. \& Lipinski, J. (1975). Biochemical aspects of schizophrenia. Annual Review of Medicine 26, 551-565.

McGuffin, P., Farmer, A. E. \& Rajah, S. M. (1978). Histocompatibility antigens and schizophrenia. British Journal of Psychiatry 132, 149-151.

Mellsop, G. W., Koadlow, L., Syme, J. \& Whittingham, S. (1974). Absence of rheumatoid arthritis in schizophrenia. South Australia and New Zealand Journal of Medicine 4, 247-252.

Nissen, H. A. \& Spencer, K. A. (1936). The psychogenic problem (endocrine and metabolic) in chronic arthritis. New England Journal of Medicine 214, 576-581.

$\emptyset$ degaard, $\emptyset$. (1951). Mortality in Norwegian mental hospitals, 1926-1941. Acta Genetica 2, 141-173.

$\emptyset$ degaard, $\emptyset$. (1952). Incidence of mental diseases measured by census investigations versus administration statistics. Psychiatric Quarterly 26, 212-218.

$\emptyset$ degaard, $\varnothing$. (1967). Mortality in Norwegian psychiatric hospitals, 1950-1962. Acta Genetica 17, 137-153.

Opsahl, R. (1933). Frequency of cancer among patients with mental diseases. Norsk Magasin for Laegevidenskapen 94, 771-790.
Österberg, E. (1978). Schizophrenia and $\mathrm{r}$ heumatic disease Acta Psychiatrica Scandinavica 58, 339-359.

Pool, A. (1930). A study of the incidence of cancer over a period of twenty-five years at the County Mental Hospital, Rainhill. RMPA Report. Journal of Mental Science 76, 234-244.

Rassidakis, N. C., Kelepouris, M. \& Fox, S. (1971). Malignant neoplasms as a cause of death among psychiatric patients. I. International Mental Health Research Newsletter, 13.

Rassidakis, N. C., Kelepouris, M., Goulis, K. \& Karaiossefidis, K. (1973). On the incidence of malignancy among schizophrenia patients. Agressologie 14, 269-273.

Reynolds, E. H. (1968). Epilepsy and schizophrenia: relationship and biochemistry. Lancet i, 398-401.

Rudolph, G. De M. \& Ashby, W. R. (1934). The relative mortality of cancer in the general population and in the mental hospitals of England and Wales. Journal of Mental Science 80, 223-276.

Sabbath, J. C. \& Luce, R. A. (1952). Psychosis and bronchial asthma. Psychiatric Quarterly 26, 562-576.

Scheflen, A. E. (1951). Malignant tumors in the institutionalized psychotic population. Archives of Neurology and Psychiatry 66, 145-155.

Shields, J. (1978). Genetics. In Schizophrenia: Towards a New Synthesis (ed. J. K. Wing), pp. 53-87. Academic Press: London.

Singh, M. M. \& Kay, S. R. (1976). Wheat gluten as a pathogenic factor in schizophrenia. Science 191, 401-402.

Slater, E. \& Beard, A. W. (1963). The schizophrenia-like psychoses of epilepsy. British Journal of Psychiatry 109, 95-150.

Smith, J. M. (1976). Letter. Science 194, 448.

Stevens, F. M., Lloyd, R. S., Geraghty, S. M. J., Reynold, M. T. G., Sarsfield, M. J., McNicholl, B., Fottrell, P. F. Wright, R. \& McCarthy, C. F. (1977). Schizophrenia and coeliac disease - the nature of the relationship. Psychological Medicine 7, 259-263.

Taylor, D. C. (1975). Factors influencing the occurrence of schizophrenia-like psychosis in patients with temporal lobe epilepsy. Psychological Medicine 5, 249-254.

Torrey, E. F. \& Peterson, M. R. (1974). Schizophrenia and the limbic system. Lancet ii, 942-946.

Tsuang, M. T. \& Woolson, R. F. (1977). Mortality in patients with schizophrenia, mania, depression and surgical conditions. British Journal of Psychiatry 130, 162-166.

Warren, S. \& Canavan, M. M. (1934). Frequency of cancer in the insane. New England Journal of Medicine 210, 739-742.

White, W. A. (1929). The social significance of mental disease. Archives of Neurology and Psychiatry 22, 873-900. 